\title{
Employee Perceptions of Organizational Culture AND Morale in ENTERPRISES Served by Professional EMPloyer Organizations: A Preliminary Assessment
}

Thomas A. Rossi

Dr. Thomas A. Rossi, Professor of Management, Utica College, trossi@utica.edu.

\begin{abstract}
Many leaders of small and medium-sized enterprises (SMEs) outsource human resource (HR) functions and activities to professional employer organizations (PEOs) to meet changing and complex HR challenges. Although most directors of SME-client organizations are satisfied with the results of HR outsourcing, employees' perspectives regarding the effect of PEO presence on organizational culture and morale have not been considered. The purpose of this qualitative study following a phenomenological approach was to discover the perceptions of employees regarding organizational culture and morale in SMEs where PEO services are used. In-depth interviews were conducted with nine nonsupervisory employees of SMEs in central New York State conducting business with a PEO. Common themes in interviewee responses were identified. The key finding derived from the study was that
\end{abstract}


participants did not perceive their PEOs as having a significant influence on either organizational culture or employee morale. Several key recommendations for future best practices will be offered.

Keywords: Organizational culture, morale, Professional Employer Organization, PEO

DOI: http://dx.doi.org/10.15239/j.brcacadjb.2018.08.01.ja04

\section{BACKGROUND}

The PEO industry was initiated in 1985, and its potential market is still relatively untapped (National Association of Professional Employer Organizations [NAPEO], 2017a). The growth rate of the overall industry from 1992 to 2002 was $386 \%$ (Lombardi \& Ono, 2008). In 2008, the industry grew by $\$ 5$ billion, to $\$ 68$ billion in gross revenues, with an increasingly diverse and rapidly growing clientele (NAPEO, 2017a). In 2015, the size of the PEO industry was between $\$ 136$ and $\$ 156$ billion, as measured in gross revenues (The State, 2016). Over the last 30 years, the industry has grown significantly. It has added an average of 100,000 worksite employees and 6,000 new clients annually (NAPEO, 2017a). There are approximately 1.1 million business in the United States that have between 10 and 99 employees. Although the PEO industry considers this as it primary target market, it can only claim approximately 14 to 16 percent of these businesses as clients (The State, 2016). With these penetration rates, the PEO industry appears to have ample room for continued growth. The industry also recognizes an opportunity for growth in a market that is significantly larger still, i.e., the market of very small firms with fewer than 10 employees. Its penetration in this market is only about 3 percent (The State, 2016).

Professional employer organizations provide owners of client organizations with integrated services enabling them to outsource the management of HR, employee benefits, payroll, and workers' compensation 
in a cost-effective manner. Many PEOs offer human capital-enhancing services, such as assistance with recruitment and selection efforts, training, employee relations, and organizational development issues. These services affect client satisfaction and an employee's decision to stay (Klaas, Gainey, McClendon, \& Yang, 2005). An adequate set of comprehensive services can be helpful to clients, particularly in attracting and retaining high-quality employees. However, the gains also depend on the content, cost, and quality of benefits and services packages offered. In addition, prospective clients need to consider the manner in which HR packages are delivered when contemplating the decision to hire a PEO (Klaas et al., 2005).

PEOs deliver services and programs using a coemployment model (NAPEO, 2017c). As coemployers, PEOs contractually assume substantial employer rights, responsibilities, and risk through the establishment and maintenance of an employer relationship with the clients' workers (NAPEO, 2017c). Although the idea of coemployment appears to run counter to the unity of command principle of management, the arrangement has worked effectively (Lombardi \& Ono, 2008). PEOs in the United States coemploy between 2.7 and 3.4 million American employees working in small and mid-sized businesses (NAPEO, 2017a).

As PEOs normally serve and represent the combined interests of numerous smaller-sized firms simultaneously, most PEOs merge clients together into larger consortiums (Buchanan, 2006). Generally, with larger consortiums, attaining a wider array of benefits at affordable costs becomes easier for participants (Lombardi \& Ono, 2008). When SMEs contract the services of a PEO, the HR function usually operates more effectively and efficiently. Consequently, SMEs are in a better position to compete with larger firms with abundant resources, and become capable of offering employees comprehensive benefits at affordable prices. In addition, SMEs that provide PEO services put themselves in a better position to attract well-qualified employees. 
The largest and most prestigious trade association for PEOs in the United States is the NAPEO (2017a). The NAPEO is comprised of nearly 350 certified member PEOs operating in all 50 U.S. states, representing approximately $90 \%$ of the revenues of the entire industry. Being able to provide services through a certified $\mathrm{PEO}$ can positively contribute to a current or prospective client's efforts at developing a competitive advantage, one rooted in reliably and quality of service. Overall, there are between 780 and 980 PEOs operating in the United States (The State, 2016). New York and all other states require PEOs to be licensed or duly registered (NAPEO, 2017a). All NAPEO member PEOs are held to strict and rigorous quality and ethical standards as stipulated by the association. Additionally, all adhere to a best practices approach to management.

Many of the clients surveyed in studies of PEO outsourcing have been large employers. Larger organizations whose leaders outsource HR functions and services to a PEO can generally afford to purchase a package of transactional and human capital-enhancing services for their employees while maintaining their own operative HR department. In addition, larger organizations can afford, and generally opt for, a strong-ties delivery model, which is more likely to enhance conditions relative to employee morale and organizational climate and culture. In contrast, because SME leaders generally follow a strict cost-minimization strategy, many would not solicit the expensive human capital-enhancing HR services offered by a PEO (Osman, Ho, \& Galang, 2011; Yu \& Wang, 2010). As an alternative, SME leaders are more likely to outsource just transactional HR services to a PEO using a weak-ties delivery model (Stroh \& Treehuboff, 2003).

Compared to transactional HR services and functions, human capital-enhancing HR services and functions are considered more expensive, time consuming, and longer term (Klaas, Gainey, et al., 2005; Klaas, Yang, Gainey, \& McClendon, 2005). These functions are seen as apart from the core benefit package commonly offered to SME employees. Employee morale and organizational culture may suffer, because employees gener- 
ally consider human capital-enhancing HR services and functions as ongoing, long-term investments in their development (Stroh \& Treehuboff, 2003).

\section{Statement of the Problem}

HR outsourcing is a growing trend, and the future demand for PEO services is likely to increase (Miller, 2006). Therefore, PEOs will continue to affect employees. Employees are integral stakeholders in the employer-PEO-employee relationship and assume an important role in the culture and climate of the organization (Klaas, 2008; Lynott, 2007). Input based on employee perceptions can be helpful in explaining organizational performance, culture, and success (Markos \& Sridevi, 2010; Trahant, 2007). Employee viewpoints also represent a fundamental component of evaluative feedback that can be used to assess and shape future associations between PEOs and current and prospective client organizations (Klaas, Gainey, et al., 2005; Klaas, Yang, et al., 2005).

The problem addressed in this study is that the known relationship of PEOs to client organizations has been based exclusively on the assessments of SME directors and supervisors (Klaas, Gainey, et al., 2005; Klaas, McClendon, \& Gainey, 2000, 2002; Klaas, Yang, et al., 2005). Most SME directors have been known to be satisfied with the services, efficiencies, and cost savings derived from outsourcing HR activities and functions to a PEO (Klaas, Gainey, et al., 2005; Klaas, Yang, et al., 2005; Klaas, 2008). However, when decisions are made to outsource HR activities and functions to a PEO, employees are likely to sense changes in organizational culture (Stroh \& Treehuboff, 2003). Employee morale may also be affected. Given the integral role of employees as stakeholders in the PEO relationship, there was a need to investigate how nonsupervisory employees perceive PEOs and whether the PEO-client relationship contributed constructively to organizational culture and employee morale (Stroh \& Treehuboff, 2003). 


\section{DEFINITION OF Key TERMS}

The following definitions and terms were used in the current study.

Coemployment. The PEO relationship involves a contractual sharing of employer responsibilities between the PEO and the client (NAPEO, 2017c). The relationship is unique in the sense that it does not follow the same level of accountability a typical third party administrator maintains with a given client ("Co-employment 101," 2018). The shared employment relationship is called coemployment. As organizations functioning as coemployers in conjunction with client companies, PEOs contractually assume substantial employer rights, responsibilities, and risk through the establishment and maintenance of an employer relationship with the workers assigned to its clients. A coemployment relationship is contractually and legally established between the PEO and client organization regardless of whether the PEO provides transactional or human capital-enhancing HR services (or both) to its coemployees.

Human capital-enhancing human resource services. Human capital-enhancing $H R$ services are also referred to as strategic $H R$ services. Human capital-enhancing HR services are strategic in nature and consist of activities relating to the HR functions of recruitment, selection, training, counseling, performance management, employee relations, and organizational development issues (Klaas, Yang, et al., 2005).

Human resource outsourcing (HRO). HRO is a discretionary process of outsourcing an organization's HR functions and activities to a third party administrator who possesses the needed knowledge and specialized skills. Outsourcing such functions as payroll and benefits administration can reduce costs, improve flexibility, and permit the hiring of specialized expertise (Ivancevich \& Konopaske, 2013).

Professional employer organization (PEO). A PEO is a company that contractually assumes and takes responsibility for managing many critical HR functions for client organizations. Managers of a PEO establish and 
maintain a coemployer relationship with worksite employees (NAPEO, 2017c).

Small and medium-sized enterprises (SMEs). A SME is typically a business with fewer than 500 employees (Ward, 2008). A small business typically has fewer than 100 employees if the firm produces goods or fewer than 50 employees if the business is service based. A firm with more than 50 employees but fewer than 500 employees is generally classified as a small to medium-sized business. The numbers vary according to the country or group of nations being considered. There is no standard definition of business size in the United States (Ward, 2008).

Strong-ties service delivery model. A strong-ties service delivery model is a model of service delivery in which personal, face-to-face interaction between clients and designated HR specialist is emphasized (Klaas, Gainey, et al., 2005).

Transactional human resource services. Transactional HR services are HR services considered clerical in nature. These services generally include payroll and benefits administration (Klaas, Gainey, et al., 2005).

Weak-ties service delivery model. A weak-ties service delivery model is the direct opposite of a strong-ties service delivery model. In a weak-ties service delivery model, client employees are encouraged to use automated call centers to obtain HR services (Klaas, Gainey, et al., 2005).

\section{RESEARCH QUESTIONS}

The following research questions were constructed to determine how nonsupervisory employees of SMEs perceived the culture and morale of their organization when HR activities and functions were outsourced to a PEO.

Q1. How do nonsupervisory employees of SMEs with a contractual relationship with a PEO describe the culture of their organization, based on personal experiences? 
Q2. How do nonsupervisory employees of SMEs with a contractual relationship with a PEO describe employee morale in their organization, based on personal experiences?

\section{ReSEARCh Methodology}

This qualitative research study followed a phenomenological design. A phenomenological approach was selected for this study because the research questions addressed the lived experiences and perspectives of the participants. Utilizing a phenomenological approach helped identify, describe, and interpret the more complex and hidden facets of employees' lived experiences with PEOs and HR outsourcing (Moustakas, 1994). Indepth, semistructured interviews were conducted with nine nonsupervisory employees of SMEs currently conducting business with a PEO. The exact number of participants was determined by the point at which data saturation was reached (Creswell, Hanson, Clark, \& Morales, 2007; Groenewald, 2004). An acceptable sample size for phenomenological research is generally two to 10 participants (Boyd, 2001; Creswell et al., 2007). All interviews were conducted face-to-face at a time and place convenient to the participant. Purposive sampling was used to select participants. All participants were located in central New York State, came from three different SMEs within the region, and were familiar and knowledgeable with all of the issues investigated.

A digital recorder was used with consenting participants to record interview conversations. Audio-recorded conversations were maintained in confidence. The integrity of the data was maintained during data transcription. Special precautions were taken to prevent technical failure from disrupting interviews. Recordings were transcribed using Dragon NaturallySpeaking (Version 10) voice recognition software. The software was designed to assist in managing and expediting the transcription process. NVivo (Version 10) qualitative analysis software was then used 
for classifying, sorting, and coding the data (QSR International Products, 2016).

Analyses were conducted using the phenomenological techniques of Epoché, phenomenological reduction, imaginative variation, and synthesis. An audit trail was constructed to provide a detailed description of the research steps taken from the start of the study to the development and reporting of the findings. The audit trail provided an opportunity to demonstrate the neutrality of the research interpretations (Hoepfl, 1997).

The data were verified in terms of credibility, transferability, dependability, and confirmability (Lincoln \& Guba, 1985). Investigator triangulation was used to ensure the integrity, richness, and accuracy of the research findings and to increase the credibility of the results (Creswell et al., 2007; Denzin \& Lincoln, 2011; Patton, 2002). All participating subjects were asked to review their own interview transcriptions for accuracy. Any statements considered inaccurate or unacceptable were deleted. All research participants were assured of informed consent, anonymity of response, and protection of subject data even after the study is completed. All data were evaluated with integrity to minimize bias.

\section{FINDINGS}

The nine participants interviewed in the study were all nonsupervisory, full-time, benefits-eligible employees currently working in a SME located in central New York State. Each of the three SMEs represented in the study was currently engaged in a business relationship with a different NAPEO-member PEO located in New York State. Based on contractual agreements reached, each $\mathrm{PEO}$ provided its client with transactional HR services (e.g., payroll and benefits administration) using a weakties delivery model.

Of the nine participants, eight were female. All but one participant had education beyond a high school diploma. Six participants had previous work experience, and four had previous experience working in a HR 
department. The three types of participating SMEs were a financial service company, a veterinary clinic, and a law office.

Types of standard benefits and HR services offered by the SMEs in this study included direct deposit, payroll deduction, and health insurance coverage using a predominant weak-ties delivery model. Types of optional benefits included $401 \mathrm{~K}$ plans and optional health insurance features containing vision and dental riders. According to P. J. Civello, Vice President of Accord Human Services Inc. (personal communication, May 28, 2013), "Based on my many years of experience, this range of transactional HR benefits accurately depicts what most PEOs offer all types of SMEs in the central New York region of the state." Although the vast majority of benefits and services made available to the SMEs in the study were of the transactional nature and delivered using a weakties delivery model, all three of SMEs used in the study also contracted and received from their respective PEOs recruitment, selection, and performance appraisal consultation assistance. A limited number of human capital-enhancing HR services and consultations, therefore, were also provided. These were delivered by PEO representatives using a strong-ties model and occurred infrequently and often sporadically during both initial and follow-up visits to the SME clients' facilities.

\section{Research Question Results}

Following is a restatement of the research questions for this study, along with a presentation of the results for each question.

Research Question 1. The first research question of this study was, How do nonsupervisory employees of SMEs with a contractual relationship with a PEO describe the culture of their organization, based on their own lived experiences? Two themes were identified in the answers to this question: (a) PEOs were not perceived to have a significant influence on the organizational culture; and (b) the culture of the organization was shaped more significantly by owners, directors, and coworkers than by PEOs. 
Theme 1: PEOs were not perceived to have a significant influence on the organizational culture. Most of the participants did not believe their PEOs and PEO representatives had a significant influence on either improving or harming the culture of their organization. This finding was unexpected, given that a PEO legally assumes the role of coemployer. As coemployers, PEOs contractually assume substantial employer rights, responsibilities, and risk through the establishment and maintenance of an employer relationship with the clients' workers (NAPEO, 2017c). Most participants revealed that their understanding of the PEO coemployment role was unclear. Participants commonly complained that the PEO and PEO representative did not really know them.

When participants were asked if they believed their PEO and PEO representative fully understood and supported their firm's organizational mission nearly all expressed uncertainty based on their lived experiences. This was an unexpected finding because mission refers to the ability of organizational leaders to identify a meaningful, clear, and long-term direction that provides employees with a common vision for the future (Denison, Janovics, Young, \& Cho, 2006; Denison \& Mishra, 1995).

Theme 2: The culture of the organization was shaped more significantly by owners, directors, and coworkers than by PEOs. Almost all of the participants identified the owners, directors, and coworkers of their organizations as most influential in shaping and maintaining the organizational culture and morale. "They know us, they work with us daily, they train us, and they support us" were common sentiments expressed.

In particular, participants cited the leadership style and the goals of the owners as being important factors in shaping organizational culture. Most of the participants appeared to be genuinely satisfied with the leadership styles, communicational levels, and consistency demonstrated by the owners and directors.

The participants also appeared to be comfortable with their relationships with the leaders and expressed gratitude that these individuals were present and available to provide immediate counsel or assistance 
when needed. All participants appreciated their employer's discretionary initiative to solicit the assistance of a PEO to provide them with an attractive package of both standard and optional HR benefits and services.

Overall, participants' responses indicated that PEOs provided a valuable and positive service to their organizations but did not play a major role in affecting organizational culture. Organizational culture, however, was perceived as being shaped predominantly by the individuals with whom they interacted on a daily basis.

Research Question 2. The second research question of this study was the following, How do nonsupervisory employees of SMEs with a contractual relationship with a PEO describe employee morale in their organization, based on personal experiences? Two themes were identified in the answers to this question: (a) PEOs were not perceived to have a significant influence on employee morale; and (b) employee morale was shaped more significantly by owners, directors, and coworkers than by PEOs or PEO representatives.

Theme 1: PEOs were not perceived to have a significant influence on employee morale. Most of the participants did not believe their PEOs and PEO representatives had a significant influence on either improving or hurting employee morale. Participants commonly complained that the PEO and PEO representative did not really know them and rarely had a visible presence in their organizations. Additionally, nearly all of the participants voiced concern and disappointment with their PEO representatives because they did not take the time to solicit employees' improvement suggestions and recommendations relative to the HR benefits packages offered and received.

Theme 2: Employee morale was shaped more significantly by owners, directors, and coworkers than by PEOs. Most of the participants in the study believed that the owners and directors of their organizations had a significantly greater influence on their personal morale and organizational commitment than the PEO or PEO representative did. Several participants commented that their leaders had helped to create a positive climate of 
cooperation, respect, family, and teamwork. Participants placed great value on knowing their owners and directors were regularly available to listen to their concerns, solicit employee input, and provide needed support and assistance. All participants agreed that employee morale was shaped more significantly by owners, directors, and coworkers than by PEOs or PEO representatives, and that the PEO had little or no effect on their morale. In contrast, $\mathrm{PEO}$ representatives were described as much more impersonal and less accessible in their dealings with employees.

Overall, participants' responses indicated that PEOs provided a valuable and positive service to their organizations but did not play a major role in affecting employee morale. Alternatively, employee morale was perceived as being shaped predominantly by the individuals with whom they interacted on a daily basis.

\section{Limitations, Conclusions, And Recommendations}

\section{Limitations}

There are a number of limitations in relation to the research. First, because of the emerging nature of qualitative research and phenomenological inquiry, participants' responses to open-ended interview questions were unpredictable. Although the semistructured interview format composed of open-ended questions paved the way for a number of emerging themes, participants may not have been able to capture all of their lived experiences within the allotted time frame. On several occasions the participants hesitated to offer responses due to personal uncertainties. For instance, many were surprisingly uncertain as to what the PEO acronym itself signified. Many of the participants were also either unaware of the coemployment role PEOs legally assume in client organizations or lacked a clear understanding of it. Consequently, researcher bias, although unintentional, may have been triggered while collecting and interpreting data. 
Second, some employees may have felt vulnerable and feared retaliation from their superiors for voicing their feelings. Consequently, some participants were relatively brief with their responses, while others were free and open to elaborate when the situation presented itself. In an attempt to mitigate this problem, all participants were assured in writing of their anonymity and confidentiality in the initial consent and agreement form and verbally at the beginning and end of each interview. Considering that member checks were used to validate interview transcripts and investigator triangulation was used to read the interview transcripts and assist with data analysis, all participants were apprised in the distributed informed consent forms of anyone who had access to the information (Hoepfl, 1997).

A third limitation regarded the size of the sample. The purposive sample size was confined to nine full-time, nonsupervisory employees of SMEs doing business with a PEO. All participants were selected from central New York State. Each SME was dissimilar according to the type of business it conducted and the nature of the work performed by its employees. Three full-time, nonsupervisory employees from each SME (or a total of nine) agreed to be interviewed. While data saturation was achieved in the data analysis, a sample size of nine participants may have limitations. The sample size was relatively small and may not be representative of the total population.

A fourth limitation is related to the subjective nature of the data. Phenomenological research naturally introduces and involves the emotional and textural aspects of participant response rather than objective, measurable behavior and attitudes (Moustakas, 1994). There is no standardized procedure for interpreting the findings and reaching conclusions. Instead, interpretations and conclusions were made based on personal judgment and experience with phenomenological research. Consequently, interpreter bias may have threatened the credibility of the study. Two triangulation experts were recruited and used, however, 
to read the interview transcripts and assist with data analysis to ensure the integrity and accuracy of the findings.

A detected fifth limitation pertained to the issue of current research literature on the topic. It was determined that a major gap in research literature exists relative to the impact PEOs have on organizational climate and culture based on the perceptions held by managers of client organizations. Existing research has yet to examine and explain how nonsupervisory employees of SME client organizations perceive the role and function of PEOs and the affect they have on organizational culture and climate. The lack of noticeable research should not automatically suggest any such degree of unimportance; instead, the matter has been overlooked for several years.

A sixth limitation is related to the unbalanced array of PEO benefits and services offered to and received by all of the participants in the study. Although the vast majority of benefits and services made available to the participants in the study were of a transactional nature and delivered using a weak-ties delivery model, all three of SMEs used in the study also contracted and received recruitment, selection, and performance appraisal consultation assistance from their respective PEOs. These were delivered using a strong-ties model, but, only occurred infrequently and often sporadically during both initial and follow-up visits to the SME clients' facilities. The value of these services were likely felt in more of an indirect manner by the participants in the study.

In summation, this qualitative research study followed a phenomenological design and the resulting analysis could be characterized by some as exploratory. This is not to say that exploratory research does not have worth; it merely implies that such research will likely be unable to produce what it does not promise. Although the study admittedly had several limitations, it is believed that each was mitigated effectively. Limitations were mitigated by using (a) epoché to prevent and block initial biases and assumptions, (b) bracketing during the phenomenological reduction process, (c) allowing the participants to validate the study's findings 
through member checks, and (d) investigator triangulation (Husserl, 1969: Hycner, 1985). In addition, all necessary precautions were taken to assure participants' anonymity. Participants were free to voice their opinions without worry of supervisory retaliation. Strict confidentiality was also consistently maintained throughout the study.

\section{Conclusions}

The following will discuss each research question individually with an identification of applicable conclusions derived.

Research Question 1.The first central research question of this study was, How do nonsupervisory employees of SMEs with a contractual relationship with a PEO describe theculture of their organization, based on their own lived experiences? Nearly all of the participants in the study expressed satisfaction with the favorable culture that existed within their respective organizations, however, mostly credited their owners and directors for this. Thus, based on participants' responses to relevant interview questions two themes emerged: (a) PEOs were not perceived to have a significant influence on the organizational culture; and (b) the culture of the organization was shaped more significantly by owners, directors, and coworkers than by PEOs.

\section{PEOs were not perceived to have a significant influence on} organizational culture. It was concluded that nearly all of the participants in the study perceived their PEOs and PEO representatives as investing only minimal, noticeable effort relative to the issue of adapting and fitting into their organization's culture. Further, it was learned that PEO representatives did not maintain a consistent physical presence within participants' organizations and only visited them occasionally, i.e., during either annual or semiannual open enrollment periods. As a consequence, $\mathrm{PEO}$ representatives were perceived as outsiders, i.e., third party administrators hired by their owners to provide HR benefits and services. This was particularly surprising, however, because PEOs are 
much more than third party administrators; they are legally considered coemployers (NAPEO, 2017c). Employees need to be made more aware of this legal coemployment relationship; therefore, PEOs and client organizations have a joint responsibility to provide essential clarity on the issue.

Another conclusion derived was that each of the SMEs involved in the study relied on its PEO to provide its employees with only transactional HR benefits and services using a weak-ties delivery model. Based on previous related research it was learned that SME leaders typically outsource transactional HR services and functions to a PEO, but, do not rely upon PEOs to provide human capital-enhancing services such as specialized training and career development (Klaas, 2003, 2008). While the decision to outsource transactional HR benefits and services is typically a strategy to minimize costs, it can affect organizational culture and employee morale positively (Stroh \& Treehuboff, 2003). While nearly all of the participants appreciated having the option of receiving transactional benefits and services, several participants were already receiving comparable transactional benefits and services through their spouses' plans with other employers. Organizational culture, therefore, was neutrally affected at best.

Another surprising conclusion derived was that nearly all of the participants seemed to be unaware of the official coemployment role PEO's typically assume. The small minority of participants who had heard of the coemployment concept perceived it as vague and rather confusing. If employees are unsure of what to expect of their PEOs and fail to understand the coemployment role PEOs legally and officially assume, they will become skeptical and a lack of trust will result (Stroh $\&$ Treehuboff, 2003). To reiterate, these issues were apparently not clarified by either the participants' SME owner or PEO representative. Either the PEO representative or the SME owners and directors should have provided the employees with a clear indoctrination of the meaning and significance of coemployment in order to avoid any confusion or future misunderstandings. This is consistent with the misconceptions 
and potential risks associated with coemployment ("Co-employment 101," 2018).

\section{Organizational culture was shaped more significantly by owners,} directors, and coworkers than by PEOs. First, nearly all of the participants in the study perceived that their organizations' culture was established by internal management and built on mutual consideration, respect, trust, open communication, and cooperation. For instance, all of the SME owners and directors were said to be approachable and accessible to employees at all times. Second, nearly all of the participants considered their leaders' styles and approaches as fair, consistent, and effective in building teamwork and a strong culture. This is consistent with the view of Cronin, Kiessig, and Sprenkle (2008) in that organizational culture is mission-driven and shaped by the ideals, philosophy, and leadership styles on top management. Third, participants' trust and confidence were determined to reside primarily in their owners and directors and not in their PEOs or PEO representatives. One explanation for this can be attributed to the discovery that nearly all of the participants perceived their PEO and PEO representative as only occasional visitors who were neither fully invested in their organization nor its mission. In contrast, participants perceived their owners and directors as being completely invested in the organization and mission which they initially established. Thus, participants gave very little credence to the role their PEOs or PEO representatives assumed with regard to organizational culture.

The SME owners' decision to outsource a number of HR programs and services to a $\mathrm{PEO}$ was perceived as a helpful and proactive measure by nearly all of the participants in the study. Overall, participants felt this contributed positively to employee morale and organizational climate; however, it did very little to improve an already strong existing culture in each of the SMEs. This view was surprising because it contradicted the view of Stroh and Treehuboff (2003) who stressed that when managerial decisions are made to outsource HR activities and functions to a $\mathrm{PEO}$, employees are likely to sense positive changes in organizational 
culture. One possible explanation for this is because all of the SME owners and directors chose to outsource only certain types of programs and services, i.e., transactional HR services (e.g. payroll and benefits administration). This was consistent with current literature revealing that SME leaders generally follow a strict cost minimization strategy due to limited resources (Osman et al., 2011; Yu \& Wang, 2010). Many SMEs cannot afford to solicit the more expensive human capital-enhancing HR services offered through PEOs (Osman et al., 2011; Yu \& Wang, 2010). Most employees appreciate and place greater value on receiving human capital-enhancing HR services and functions (e.g., training and development) because these types of benefits are considered longer-term investments in their development (Stroh \& Treehuboff, 2003). All of the SME owners and directors involved in the study personally provided their employees with these types of benefits with minimal PEO intervention and assistance. This contributed to further enhancing the employeemanagement relationships that were already perceived as strong by the participants.

Research Question 2. The second central research question of this study was, How do nonsupervisory employees of SMEs with a contractual relationship with a PEO describe employee morale in their organization, based on personal experiences? Nearly all of the participants in the study were satisfied with existing employee morale, however, credited their owners and directors for their direct and positive influence. Thus, based on participants' responses to relevant interview questions two themes emerged: (a) PEOs were not perceived to have a significant influence on employee morale; and (b) employee morale was shaped more significantly by owners, directors, and coworkers than by PEOs or PEO representatives.

\section{PEOs were not perceived to have a significant influence on} employee morale. Nearly all of the participants voiced satisfaction with the prevailing level of employee morale experienced within their respective organizations. All participants, however, credited their owners and directors with making the highest contributions to employee morale. 
Based on nearly all of the participants' expressed perceptions, little credence was given to the role assumed by the PEO relative to its influence on employee morale. Nearly all of the participants perceived their $\mathrm{PEO}$ and PEO representative as having either a neutral effect on employee morale and organizational commitment or very little effect at all. Two possible explanations exist for these perceptions. First, nearly all of participants either did not fully comprehend the implications associated with the coemployment role PEOs legally assume or were merely unacquainted with them. If employees fail to understand what coemployment entails, they will likely find it difficult to assess the PEO's influence on their morale. Second, nearly all of the participants felt their morale was affected more by such key factors as (a) the effective and consistent leadership of their owners and directors, (b) the organizational culture established by their owners and directors, (c) an encouraging and comfortable work environment, and (d) positive coworker relations and teamwork. The factors were found to be consistent with what appears in the literature relative to what contributes positively to employee morale (Denka, 2009).

Interestingly, the majority of participants felt their PEOs and PEO representatives did not really know or care about them as individuals. "They don't know us and we don't know them; so, how could they care about us?" was a common subtheme that emerged during data coding and analysis. Most of the participants perceived their relationship with the PEO representative as cold, superficial, and detached. This can be attributed to the infrequency of interaction, particularly of the face-to-face sort, between the two parties. A smaller number of participants even perceived their PEOs and PEO representatives as external, third-party HR service providers hired and contracted for the sole purpose of serving the owners and directors of their organizations. All of this seems consistent with Chaftkin's (2006) view that the HR function becomes far less personalized when SMEs become partners with PEOs and as a consequence employees lose the personal touch many appreciate having. These views, however, did not support the views of Ivancevich and Konopaske (2013) that HR services providers, whether in-house or outsourced, must attempt to care 
for each employee as an individual and genuinely address and satisfy his or her needs. Surprisingly, the participants' perceptions of PEOs and PEO representatives not caring about them did not appear to adversely affect overall employee morale. The reason is because the nearly all of the participants believed their organizational owners and directors had a much greater and influential impact on morale and were considered the drivers of the existing organizational culture.

\section{Employee morale was shaped more significantly by owners, directors, and coworkers than by PEOs or PEO representatives.} Most of the participants in the study genuinely appreciated their owners' voluntary efforts to provide them with an array of optional and affordable HR benefits and services not always made available to employees working in smaller firms. It was surprising, however, to discover, that three (or one third) of the participants opted only for the minimal HR benefits and services package offered which consisted of payroll benefits only. It was learned, however, that these employees were receiving all other benefits through their spouses' higher quality and more economically affordable plans with other employers.

When interviewed, nearly all of the participants expressed the feeling that their PEO and PEO representative gave them minimal attention and showed insufficient interest in meeting their individual HR-related needs. A major reason for this was because participants' input went unsolicited; particularly regarding the types of HR benefits and services participants valued and desired most. Although many of the participants appreciated having the option of selecting and purchasing PEO-provided benefits and services, most perceived their PEOs as unwilling to listen to employee suggestions. Thus, a common concern expressed by nearly all of the participants in the study was that their feedback was never solicited by PEO representatives during infrequent meeting visits to their workplaces. Visits were typically made during once or twice a year during open enrollment periods to allow employees to select new benefits and services or make changes in the packages they already received. Based on the vast 
majority of participants' responses, it was ascertained that these meetings were held for the sole purpose of furnishing employees with specific, quantifiable information. While it was also learned that employees were given an opportunity to ask clarification-type questions during these informational meetings, their recommendations and suggestions relative to the types of benefits and services they valued and desired mostly were never solicited. Nearly all of the participants commented that in the absence of a true dialogue, the information addressed at these meetings could have been simply conveyed to them by either official letter or email.

According to Denison et al. (2006), employees who are allowed to provide input and participate in program decision making gain an increased sense of responsibility and ownership. Morale is likely to decline if employees are denied the opportunity to make improvement suggestions. The findings of this study did not confirm that the roles assumed by the PEO and PEO representative affected employee morale and organizational commitment in an adverse way. One simple explanation for this is because the SME owners and directors overcompensated for many of the perceived shortcomings of the PEO and PEO representative by engaging their employees, allowing them to participate in decision making activities, and assuming a stronger of influencing employee morale. Consistent with existing literature, employees should be provided the opportunity to make reasonable improvement suggestions and participate in the creation of programs that affect them personally (Denison et al., 2006). Employee suggestions and recommendations embody a vital component of evaluative feedback that can be used to assess and shape future relationships between PEOs, and client organizations, and employees (Klaas, Gainey, et al., 2005; Klaas, Yang, et al., 2005).

Another possible explanation why employees' input went unsolicited at annual and semiannual meeting visits by PEO representatives might be attributed to the nature and specificity of the contract existing between the SME owner and the applicable PEO. Because a PEO's primary responsibility is to effectively meet the needs of its client organization, some 
contracts might not explicitly contain a provision for allowing and soliciting employee input (Woodall, Scott-Jackson, Newham, \& Gurney, 2009). Alternatively, if employees wish to make suggestions for improving their HR benefits package, they may be required to consult with their employer first, who in turn, would renegotiate the existing agreement with the PEO (Lombardi \& Ono, 2008). This study was not able to demonstrate that the participants were privy to any of the details of the SME-PEO contract.

Finally, nearly all of the participants felt that the types of PEO-benefits and the model used to deliver them did very little to affect personal morale and organizational commitment. During the data collection and analysis phases of the study, it was determined that while all participants in the study were offered the opportunity to purchase and receive affordable standard and optional HR benefits and services, mostly all were classified as transactional in nature. Transactional HR benefits and services are highly standardized and include payroll and benefits administration (Klaas, 2008). Alternatively, the human capital-enhancing HR services many PEOs provide, e.g., specialized employee training and development, are more likely to be purchased by larger client organizations that can afford these strategic services while simultaneously maintaining their own in-house HR Department (Osman et al., 2011; Yu \& Wang, 2010).

Prior research has indicated that because leaders of SMEs generally follow a strict cost minimization strategy, they are more likely to outsource only transactional HR services to a PEO using a weak-ties delivery model (Osman et al., 2011; Yu \& Wang, 2010; Stroh \& Treehuboff, 2003). Thus, it was not surprising that the owners and directors of all three of the SMEs involved in the study were predominantly following a similar practice which is consistent with existing literature.

Nearly all of the HR benefits and services offered to participants of the study in their employee packages were delivered using a weak-ties model. A weak-ties service delivery model is one in which employees are encouraged to use automated call centers to obtain HR services (Klaas, Gainey, et al., 2005). Nearly all of the participants seemed to 
perceive the weak-ties delivery model as tolerable, but preferred to receive a more reasonable balance of personal interaction with their PEO representative and the necessity of using the PEO's website for obtaining pertinent information. The majority of participants appeared uncomfortable, however, with having to initiate most of the regular contact and interaction with PEO representatives and staff members. This is a common phenomenon experienced when weak-ties models are used to deliver HR benefits and services (Klaas, Yang, et al., 2005). A weak-ties approach is often criticized for being cold and impersonal (Klaas, Gainey, et al., 2005; Klaas, Yang, et al.).

In summation, the participants in the study did not perceive either the PEO representative or the coemployment role assumed by the $\mathrm{PEO}$ within their organization as having clear or noteworthy influence on employee morale. Alternatively, the vast majority of participants perceived their organizations' owners and directors having a significant and positive impact on employee morale. Based on their lived experiences with the owners and directors, most of the participants appeared to be genuinely satisfied with their leadership styles, communicational effectiveness, and fairness and consistency demonstrated. The majority of the participants also appeared to be comfortable with their relationships with their owners and directors and knowing they were present and available to provide immediate counsel or assistance when needed. Finally, while nearly all of the participants in the study appeared generally satisfied with the HR benefits and services offered, the majority did not perceive the PEO-provided services having much of an impact on their morale and job commitment.

\section{RECOMMENDATIONS}

The following recommendations are suggestions for action. All recommendations were based upon the findings learned from the study and the results ascertained from applicable research literature. They are 
presented to address specific needs for (a) recommendations for practice, and (b) recommendations for future research.

Recommendations for practice. The following recommendations are proactive proposals for future action. They are based upon the findings learned from the study and the results ascertained from supporting research literature. Each recommendation is supported further with specific correlating suggestions. Careful consideration was given to the limitations associated with the research when developing these recommendations.

Recommendation 1. It is recommended that PEOs and PEO representatives assume more of an active role as coemployer and contribute more constructively to their SME client organizations' culture. First, PEOs cannot allow themselves to be perceived by clients' employees as outsiders or remote third party administrators. Nearly all of the participants in the study felt their PEOs and PEO representatives had the ability to fit within the culture of their organizations, but for some unknown reason, cared not to. It is recommended they invest more time and effort learning, supporting, and adapting to their client organizations' culture. As coemployers, PEOs and PEO representatives need to show SME clients' employees that they genuinely care about them and want to get to know them and their needs better. It is in the best interests of the applicable PEO and PEO representative, therefore, to avoid treating employees as if they were merely numbers. Whenever possible they should treat each employee as an individual (Ivancevich \& Konopaske, 2013). As coemployers, PEO representatives have an obligation to be more accessible, which in turn, will demonstrate that they care. One of the SMEs in the study was found to be doing business with a PEO located less than four miles away. Its employees only had direct contact with its representative on an annual basis.

Whenever feasible, it is suggested that PEO representatives extend the number of scheduled face-to-face visits during the year. One or two additional meaningful visits per year could make a significant difference 
to employees. As an alternative to increasing the number of physical visits to client's workplaces, PEO representatives might consider scheduling and conducting a couple of extra meetings during the year with employees through the use of teleconferencing or by providing webinars. Many electronic mail providers today have launched Skype-like features that allow subscribed customers to participate in teleconferencing activity free of charge. Although virtual meetings have become a common practice in today's business world, nothing still takes the place of face-to-face communication (Daft \& Marcic, 2017).

Second, the coemployment role PEOs legally assume in clients' organizations also needs to be clarified for all employees. Nearly all of the participants in the study appeared to lack sufficient awareness and knowledge of this important issue. Employees need to know how the coemployer functions and fits within their organization and how it contributes to its culture. Open and effective conveyed communication contributes positively to any organization's culture (Cronin et al., 2008). The employer and coemployer (PEO) are jointly responsible for explicating the PEO's role to employees regarding its level of assumed authority and responsibility in the PEO-SME client-employee relationship. Although it is suggested this be accomplished during an employee's early indoctrination period with the firm, it is just as important for employees to be reminded periodically of the relationship's significance.

Third, it is also suggested that PEOs and PEO representatives need to become familiar with and fully support its client organizations' mission and mission statement. If such a document does not formally exist or requires updating, the $\mathrm{PEO}$ can help to create one in close collaboration with its client's leaders. An effective mission identifies a meaningful, clear, and long-term organizational direction that provides employees with a common vision for the future (Denison et al., 2006). Thus, employees must also be familiar with its employer's mission statement. It is an important issue that needs to be discussed during employee orientation and revisited periodically with the workforce. Employees who are able to 
identify with the mission, values, and goals of their organization are likely to become more goal-oriented themselves (Casida, 2008). In addition, they are likely to become more committed and productive. All relevant stakeholders of the organization must be fully aware of its organizational mission and core values (Casida, 2008). The mission statement should appear in an employee handbook made accessible to all employees. Only one of the three SMEs involved in the study had an employee handbook; unfortunately, it did not contain the organization's mission statement. Handbook creation and development is also a common function provided by most PEOs. To help insure awareness, it is suggested that PEO-SME client contracts contain a stipulation that require $\mathrm{PEO}$ executives and representatives to be familiar with its client organizations' mission before designing and recommending an HR benefits \& services package.

Recommendation 2. It is recommended that PEOs and PEO representatives constructively shape employee morale by engaging its client organizations' employees more, providing additional opportunities for closer interaction, and improving communicational channels. As previously discussed, all participants in the study described their direct, faceto-face contact with PEO representatives as infrequent, i.e., typically limited to one or perhaps two visits per year. Visits were said to coincide with applicable open enrollment periods. It was also discovered that these meetings were organized for the sole purpose of giving new and updated information to the employees. Participants noted that while they were allowed to ask questions to gain clarity and understanding of topics addressed during the meetings, nearly all stated that their personal input, i.e., suggestions and recommendations, was never solicited. Unfortunately, this is a common phenomenon experienced when PEOs use weak-ties models to deliver transactional HR benefits and services (Klaas, Yang, et al., 2005). All of the PEOs involved in the study were determined to be following this approach.

First, based on the review of participants' perspectives and commentaries, PEOs and PEO representatives need to make more of a conscious 


\section{The BRC Academy Journal of Business Vol. 8, No. 1}

effort to seek employees' input whenever possible, but particularly during either annual or semi-annual visits to their workplaces. Visits to clients' workplaces should not be scheduled for the sole purpose of giving employees information. PEO representatives need to encourage more of a dialogue. Furthermore, it is recommended that coemployers and employers alike engage employees by soliciting their suggestions and recommendations as to the types of HR benefits and services they value and desire to receive and by allowing them to participate in decisions affecting them personally. When employees are allowed to provide input and participate in decisions affecting them personally, they gain a sense of responsibility and ownership which generally results in greater organizational commitment and employee morale (Markos \& Sridevi, 2010; Trahant, 2007). Mutual trust and consideration can become threatened, however, when PEOs and PEO representatives fail to solicit and listen to the unique concerns and needs of their clients and clients' employees.

Second, immediately following the PEO representatives' semiannual or annual onsite visits, SME owners and directors should meet with their PEO representative to discuss and evaluate all solicited employee input. If the parties reach a consensus of agreement, i.e., the employee suggestions and recommendations are judged as meritorious and economically feasible, steps can then be taken to negotiate them into the current or subsequent PEO-SME client contract. Otherwise, employees who took the time to voluntarily provide their input are owed an explanation for the joint decision not to take action. It is suggested that this be communicated to employees within a reasonable amount of time. Following successful negotiations and reach agreements, changes stemming from employees' suggestions can then be applied. Afterwards, employee engagement efforts should be assessed jointly by the employer and coemployer to determine whether desired outcomes were successfully achieved.

Third, it is recommended that PEO representatives attempt to provide employees with more individualized support and care. Although the PEOs involved in the study were determined to be serving the HR needs 
of multiple clients and employees, it is ill-advised for them to treat employees as merely numbers. Ivancevich \& Konopaske (2013) support the position that whenever possible, HR providers should treat each employee as an individual and offer the programs and services to meet their personalized needs. Employees, however, commonly need assistance and guidance when purchasing optional HR benefits and services because of their incremental cost. The PEO representative must anticipate and be thoroughly prepared to supply this needed assistance. If PEOs and $\mathrm{PEO}$ representatives are perceived by employees as caring and sincere, a relationship of mutual trust and consideration can successfully be built (Ghassemieh, Thach, \& Gilinsky, 2005). As a consequence, employee morale is affected positively (Stroh \& Treehuboff, 2003).

Fourth, when PEOs use a weak-ties platform to deliver contractually negotiated HR benefits and services, it is recommended that employees be furnished with adequate instructional training and periodic refreshers on how to efficiently and effectively use it. Consequently, this can positively influence overall employee satisfaction and morale (Klaas, Gainey, et al., 2005). The initial and ongoing training can be conducted either online or during one of the personal visits PEO representatives make to a client's workplace during the year. It is also suggested that PEOs make these platforms more user friendly by taking the necessary steps and precautions to insure that automated call and response centers function effectively. This can be accomplished by providing employees with prompt, dependable, and consistent service of high quality.

In conclusion, it is clearly understood that all of these recommended courses of action will require additional commitment, effort, and resources from the parties involved. Before any of these suggestions can be realistically implemented, PEOs and client organizations must carefully negotiate and reach agreement on any or all of these items based on mutual feasibility. PEOs as coemployers, however, have an obligation to serve client organizations and their employees in a proactive manner instead of sitting back passively waiting for challenges to occur and then 
merely reacting to them. Being proactive is about taking responsibility for accepting challenges and working to improve the things within one's power (Daft \& Marcic, 2013). Thus, PEOs must attempt to be proactive by working closely with client organizations' leaders to develop a cohesive partnership to ensure that the best interests of the organization and its most important assets (its people) are effectively addressed. All of the recommendations for practice were focused on doing what is best for the organization and its human capital.

Recommendations for future research. Findings from this research study revealed a need to explore employee perceptions and viewpoints and how they represent a critical component of evaluative feedback that can be used to shape future associations between PEOs and client organizations (Ivancevich \& Konopaske, 2013; Markos \& Sridevi, 2010). The following recommendations for future research describe the types of studies that could be conducted to address some of the remaining gaps in literature still resulting from this study.

One recommendation is to investigate the perceptions of PEO executives and field representatives relating to the influence they have on SME client organizations' culture and employee morale. Until this study was conducted, previous research focused solely on the views of SME owners and directors based on their levels of satisfaction with PEOs and HR outsourcing (Klaas, Gainey, et al., 2005; Klaas, Yang, et al., 2005; Klaas, 2008). It would also be interesting to learn if PEOs and PEO representatives actually take the time to learn and demonstrate support of their clients' mission. All relevant stakeholders of the organization, particularly a coemployer, must be fully aware of and support its organizational mission and core values (Casida, 2008).

A second recommendation is to investigate the impact PEO utilization has on organizational culture and employee morale within an adequate sample of SMEs performing a similar service. One of the limitations of this study was that each SME was dissimilar according to the type of business it conducted and the nature of the work performed by its 
employees. Three nonsupervisory employees coming from three different services oriented SMEs, i.e., a total of nine participants, comprised this study's sample. While data saturation was achieved in the data analysis, a sample size of nine participants may have limitations. Thus, instead of having a small number of participants coming from dissimilar service organizations, a future study could focus on employee perceptions of PEOs in a specific type of service organization, e.g., financial services or legal services. Also, future studies could potentially focus on employee perceptions of PEOs in SMEs that perform manufacturing functions. This could pave the way for yet another type of study, i.e., a comparison of employees' perceptions of PEOs in SMEs that perform service and manufacturing functions.

\section{REFERENCES}

Babcock, P. (2005). PEO options and vendor evaluation. In SHRM's HR Outsourcing Focus Area. Retrieved from http://www.shrm.org/ hrdisciplines/Pages/CMS_014472.aspx

Boyd, C. (2001). Phenomenology: The method. In P. L. Munhall (Ed.), Nursing research: A qualitative perspective (3rd. ed., pp. 93-122). Sudbury, MA: Jones and Bartlett.

Buchanan, D. (2006). PEOs offer big-company benefits to small businesses. Employee Benefit Plan Review, 60(8), 13-15. Retrieved from http://www. aspenpublishers.com/product.asp?catalog_name=Aspen\&product_ id $=$ SS00136808

Casida, J. (2008). Linking nursing unit's culture to organizational effectiveness: A measurement tool. Nursing Economics, 26(2), 106-110. Retrieved from http://www.nursingeconomics.net/cgi-bin/ WebObjects/NECJournal.woa/wa/viewSection?s_id=1073744468

Chafkin, M. (2006). Fed up with HR? INC. Magazine, 28(5), 52. Retrieved from http://www.inc.com/magazine/20060501/handson-human.html

Co-employment 101. (2018). Retrieved from Insperity: Inspiring business performance website: http://www.inspirity.com 
Creswell, J., Hanson, W., Clark, V., \& Morales, H. (2007, March). Qualitative research designs: Selection and implementation. The Counseling Psychologist, 35, 236-264.

Cronin, B., Kiessig, R., \& Sprenkle, W. (2008). Recruiting and retaining staff through culture change. Corrections Today, 70(4), 48-51. Retrieved from http://www.aca.org/fileupload/177/ahaidar/Cronin.pdf

Daft, R. L., \& Marcic, D. (2017). Motivating employees. In Understanding management (10th ed., pp. 481-517). Mason, OH: South-Western, Cengage Learning.

Denison, D., Janovics, J., Young, J., \& Cho, H. J. (2006, January). Diagnosing organizational cultures; Validating a model and method [White Paper]. Retrieved from Denison Consulting, LLC website: http://www.denisonconsulting.com/Libraries/Resources/Denison-2 006-Validity.sflb.ashx

Denison, D., \& Mishra, A. (1995, March/April). Toward a theory of organizational culture and effectiveness. Organization Science, 6, 204-223. doi:10.1287/orsc.6.2.204

Denka, A. (2009, September/October). Boosting employee morale: Luxury or bottom-line concern in today's economy. Corporate Finance Review, 14(2), 16-19. Retrieved from http://ria.thomsonreuters.com/EStore/ detail.aspx?ID=CMJP

Denzin, N., \& Lincoln, Y. (Eds.). (2011). The Sage handbook of qualitative research. Thousand Oaks, CA: Sage.

Ghassemieh, G., Thach, L., \& Gilinsky, A. (2005). Does my business need a human resources function? A decision-making model for small and medium-sized firms. New England fournal of Entrepreneurship, 8(1), 25-36. Retrieved from http://www.sacredheart.edu/download/1129_ neje_spring05.pdf

Groenewald, T. (2004). A phenomenological research design illustrated. International fournal of Qualitative Methods, 3(1). Article 4. Retrieved from http://www.ualberta.ca/ iiqm/backissues/3_1/pdf/groenewald. pdf

Hoepfl, M. (1997). Choosing qualitative research: A primer for technology education researchers. Fournal of Technology Education, 9(1), 1-16. 
Retrieved from http://scholar.lib.vt.edu/ejournals/JTE/v9n1/pdf/ hoepfl.pdf

Husserl, E. (1969). Ideas: General introduction to pure phenomenology (W. R. B. Gibson, Trans.). London, England: Allen \& Unwin.

Hycner, R. H. (1985). Some guidelines for the phenomenological analysis of interview data. Human Studies, 8, 279-303. doi:10.1007/BF00142995

Ivancevich, J., \& Konopaske, R. (2013). Human resource management (12th ed.). New York, NY: McGraw-Hill Irwin.

Klaas, B. (2003). Professional employer organizations and their role in small and medium enterprises: The impact of HR outsourcing. Entrepreneurship Theory and Practice, 28(1), 43-61. doi:10.1111/15408520.00031

Klaas, B. (2008). Outsourcing and the HR function: An examination of trends and developments within North American firms. The International Journal of Human Resource Management, 19, 1500-1514. doi:10.1080/09585190802200

Klaas, B., Gainey, T., McClendon, J., \& Yang, H. (2005). Professional employer organizations and their impact on client satisfaction with human resource outcomes: A field study of human resource outsourcing in small and medium enterprises. Fournal of Management, 31, 234-254. doi:10.1177/0149206304271761

Klaas, B., McClendon, J., \& Gainey, T. (2000). Managing HR in the small and medium enterprise: The impact of professional employer organizations. Entrepreneurship: Theory and Practice, 25, 107-124. Retrieved from http://www.blackwellpublishing.com/journal.asp? ref $=1042-2587$

Klaas, B., McClendon, J., \& Gainey, T. (2002). Trust and the role of professional employer organizations: Managing HR in small and medium enterprises. Journal of Managerial Issues, 14, 31-48. Retrieved from http://www.pittstate.edu/department/economics/journal-ofmanagerial-issues/

Klaas, B., Yang, H., Gainey, T., \& McClendon, J. (2005). HR in the small business enterprise: Assessing the impact of PEO utilization. Human Resource Management, 44, 433-448. doi:10.1002/hrm.20083 
Lincoln, Y., \& Guba, E. (1985). Naturalistic inquiry. Newbury Park, CA: Sage.

Lombardi, B., \& Ono, Y. (2008). Professional employer organizations: What are they, who uses them, and why should we care? Economic Perspectives,32(4), 2-14. Retrieved from http://www.chicagofed.org/ webpages/publications/economic_perspectives/ index.cfm

Lynott, W. (2007). Help without headaches. Dermatology Times, 28(1), 146. Retrieved from http://www.modernmedicine.com/modernmedicine/ Dermatology/home/40160

Markos, S., \& Sridevi, M. (2010, December). Employee engagement: The key to improving performance. International fournal of Business and Management, 5(12), 89-96. Retrieved from http://www.ccsenet.org/ ijbm

Miller, S. (2006). What's core anymore? Outsourcing HR is sign of changing business model. Retrieved from http://www.shrm.org/ hrdisciplines/Pages/CMS_016519.aspx

Moustakas, C. (1994). Phenomenological research methods. Thousand Oaks, CA: Sage.

National Association of Professional Employer Organizations. (2017a). Industry statistics. In What is a PEO? Retrieved from http://www. napeo.org/peoindustry/industryfacts.cfm

National Association of Professional Employer Organizations. (2017b). Find a member PEO. In Directory of NAPEO members. Retrieved from http://www.napeo.org/find/members.cfm

National Association of Professional Employer Organizations. (2017c). Coemployment. In What is a PEO? Retrieved from http://www.napeo. org/peoindustry/coemployers.cfm

Osman, I., Ho, T., \& Galang, M. (2011, February). Are human resource departments really important? An empirical study on Malaysian small and medium enterprises (SMEs) in the service sector. International Journal of Business and Management, 6(2), 147-153. Retrieved from http://www.ccsenet.org/journal/index.php/ijbm/index 
Patton, M. (2002). Qualitative research and evaluation methods. Newbury Park, CA: Sage.

QSR International Products. (2016). About NVivo 10. Retrieved from

http://www.qsrinternational.com/products_nvivo.aspx

Stroh, L., \& Treehuboff, D. (2003). Outsourcing HR functions: When and when not to go outside. Journal of Leadership \& Organizational Studies, 10(1), 19-28. Retrieved from http://jlo.sagepub.com/

The state of the PEO industry: Markets, value, and trends [White paper]. (2016, September). Retrieved from https://www.napeo.org/docs/ default-source/white-papers/white-paper-2016.pdf?sfvrsn=4

Trahant, B. (2007, Spring). Debunking five myths concerning employee engagement. The Public Manager, 36(1), 53-60. Retrieved from http:// www.the publicmanager.org

Ward, S. (2008). SME. In About.com: Small business, Canada. Retrieved from http://sbinfocanada.about.com/od/businessinfo/g/SME.htm?p=1

Woodall, J., Scott-Jackson, W., Newham, T., \& Gurney, M. (2009). Making the decision to outsource human resources. Personnel Review, 38, 236-252. doi:10.1108/00483480910943313

Yu, X., \& Wang, W. (2010, November). On key points of financial cost management in small and medium-sized enterprises. International fournal of Business and Management, 5(11), 177-182. Retrieved from http://www.ccsenet.org/journal/index.php/ijbm/article/view/8077

\section{Citation Information}

Rossi, Thomas A. "Employee Perceptions of Organizational Culture and Morale in Enterprises Served by Professional Employer Organizations: A Preliminary Assessment." The BRC Academy fournal of Business 8, no. 1 (2018): 67-101. http://dx.doi.org/10.15239/j.brcacadjb.2018.08.01.ja04 